\title{
Historical Review of Plutonium Storage Container Failures at Lawrence Livermore National Laboratory
}

\author{
Karen E. Dodson \\ Isotope Separation and Advanced Manufacturing Program \\ Lawrence Livermore National Laboratory \\ Livermore, California 94550
}




\section{DISCLAIMER}

This report was prepared as an account of work sponsored by an agency of the United States Government. Neither the United States Government nor any agency thereof, nor any of their employees, make any warranty, express or implied, or assumes any legal liability or responsibility for the accuracy, completeness, or usefulness of any information, apparatus, product, or process disclosed, or represents that its use would not infringe privately owned rights. Reference herein to any specific commercial product, process, or service by trade name, trademark, manufacturer, or otherwise does not necessarily constitute or imply its endorsement, recommendation, or favoring by the United States Government or any agency thereof. The views and opinions of authors expressed herein do not necessarily state or reflect those of the United States Government or any agency thereof. 


\section{DISCLAIMER}

Portions of this document may be illegible in electronic image products. Images are produced from the best available original document. 


\title{
Historical Review of Plutonium Storage Container Failures at Lawrence Livermore National Laboratory
}

\author{
Karen E. Dodson
}

\section{EXECUTIVE SUMMARY}

As part of the DOE Plutonium Vulnerability Assessment, an investigation was made to characterize the can failures at LLNL. Since the LLNL Plutonium Facility was opened for plutonium operations in 1961, there have only been three can failures that could be remembered by plutonium handlers, vault workers, chemical analysts, and material managers. Only one of these can failures was discovered during the processing of more than 606 packages containing plutonium as part of the LLNL Plutonium Inventory Reduction Program. A very low failure rate, especially since some of the 606 cans had been in storage for two to three decades.

Two of the three containers that failed were made of aluminum and were packaged with 1.25 inch diameter plutonium metal spheres. The cans were split down their entire length and the plutonium metal was heavily oxidized. The secondary gallon. container of the third package failure was found to be imploded in the storage vault. Upon closer examination, the plastic bags around the inner pint can were badly melted and the lid on the can was loose. Like the other two failures, the metal was heavily oxidized.

In all three of the can failures, it is theorized that air entered the inner can through incomplete sealing and the oxygen in the air then reacted with the plutonium metal to produce plutonium oxide. Air was supplied to the inner can by permeation through the surrounding plastic bag. The air could have either diffused through the bag or could have been pumped through the twisted and taped ends of the inner most bag. Pumping action occurrs with changes in atmospheric pressure. The inner bags and cans were packaged into second bags and cans in an air atmosphere; therefore, trapping air inside the packaging configuration that could have passed through the bags. A failure of the inner can integrity would be necessary for the air to pass into it. In all three LLNL can failure cases, it is believed that the seal of the inner can was not sufficient to prevent a breach of the can environment.

Many labels and plastic bags have been found to be discolored or partially destroyed, and there were two situations where heavy oxidation of the plutonium metal was observed but the cans remained intact. A 1.97 kilogram metal button packaged in a long term storage can made of stainless steel was found to be completely oxidized after 
being stored for 16 months in a storage vault. Many other metal buttons stored in similar cans for several years were found to be oxide free; therefore, it is believed that the lid was not sealed properly to the can. Nominal 2.2 kilogram metal ingots wrapped in aluminum foil were packaged at the Rockwell Hanford Operations. Most of the packages contained inner cans that were food pack cans with crimp seals that had to be opened with a can opener. All the inner wrapped ingots were found to be partially oxidized with oxide inside and outside the aluminum foil. 


\section{INTRODUCTION}

As part of the Department of Energy (DOE) Initiative to evaluate the environment, safety, and health (ES\&H) vulnerabilities stemming from plutonium operations and storage, an investigation has been made at Lawrence Livermore National Laboratory (LLNL) to characterize any plutonium storage can failures encountered since operations in the LLNL plutonium facility were begun in 1961. Plutonium handlers, vault workers, chemical analysts, and material managers were interviewed to identify can failures. Even though many cans have been found with discolored labels or failed plastic bags, the interviewees remembered only three actual can failures. Two of the can failures were documented while the third was not, but the plutonium handler that discovered the can failure was able to recall most of the details. The first documented can failure was discovered in 1986 and the second one in 1992. The third can failure occurred sometime in the mid 1980's and was identical to the can failure that was discovered in 1992.

An incident report was filed on the 1986 can failure because the can had imploded in the storage vault. The storage can was still intact; therefore, there was no plutonium release or contamination. In the 1992 case, the inner storage can failure was discovered after it was removed from the secondary (outer) storage can inside a glove box. The incident was noted and photographs were taken of the failed can and its contents.

From January 1992 through September 1993, LLNL processed more than 1600 items in 606 cans for shipping and interim storage as part of the LLNL Plutonium Inventory Reduction Program. The 1992 can failure was the only one encountered during the processing of the 606 cans, an approximately $0.2 \%$ failure rate. Some of the 606 cans contained material that was packaged decades before the Plutonium Inventory Reduction Program was initiated and the packages opened.

The purpose of this report is to describe the LLNL can failures. Additionally, a description of non can failure events will be described. In these events, metal was found to be heavily oxidized but the inner can did not fail and containment was not breached; however, the information may be useful to other DOE complexes that have material packaged in similar cans.

\section{PLUTONIUM STORAGE CAN FAILURES}

1992 Can Failure

In October 1989, four plutonium metal spheres like those shown in Figure 1 were packaged into a seamless aluminum can under an inert argon atmosphere. The can's screw top lid held an organic coated cardboard insert; there was no rubber type seal in the 
lid. After the aluminum can was filled with the 1108 grams of plutonium spheres, it was bagged out of the plutonium glove box into a bag-out bag made of polyvinyl chloride that was twisted and taped at both ends. The can and bag-out bag were next placed into a second plastic bag made of polyethylene that was tied off at the opening. As shown in Figure 2 , the can and plastic bags were finally placed into a one gallon paint can that was stored in a vault until June 1992 (32 months in storage). There would have been air in the second plastic bag and one gallon can because they were packaged outside the glove box. The package was retrieved from the vault for processing as part of the LLNL Plutonium Inventory Reduction Program. It was bagged into a glove box where the gallon can was opened and the inner can and plastic bags were removed. There was no indication of any failure of the plutonium packaging observed at the outer can or plastic bags; however, the inner can was found to be split down its length as shown in Figure 3. Approximately 622 grams of the metal spheres had oxidized, equivalent to 705 grams plutonium oxide $\left(\mathrm{PuO}_{2}\right)$. Because the can was seamless, a weld failure was ruled out. The screw top lid appeared to be tight; however, the aluminum cans have pressed threads on the can and lid that do not screw together smoothly. Additionally, the cardboard in the lid does not provide a good seal between the lid and can. Therefore, air probably leaked to the inside of the can at the lid or through an undetectable pin hole. The source of air to the inner can would have been through the taped ends of the bag-out bag, or through the bag itself. As the atmospheric pressure changed with changing weather, the bags would have been pumped allowing the transport of air through the inner plastic bag and into the aluminum can where consequently, the metal was oxidized. This oxidation process was probably a slow one that occurred over a period of many months.

Over pressurization most likely caused the can failure because the volume of oxide can be more than twice that of the plutonium metal consumed in the reaction. The volume of the aluminum can was approximately 107 cubic centimeters. The original metal spheres would have had a volume of approximately 56 cubic centimeters. The remaining metal would consume approximately 25 cubic centimeters of the can volume, and the oxidized metal would have consumed approximately 62 cubic centimeters. There should have been approximately 20 cubic centimeters of the can volume remaining; however, because of the caking nature of plutonium oxide, it does not behave as a freeflowing powder that would fluff up to fill the remaining can volume. Thus a horizontal pressure of the plutonium oxide formation initiated the can split. Los Alamos National Laboratory personnel have also documented the plutonium oxide caking and horizontal 
growth of oxide in a steel storage container. ${ }^{1}$ Once the failure of the can was initiated, continuation of the split would have taken little force because of the low strength of aluminum metal.

\section{Mid 1980's Can Failure}

Another can failure that occurred sometime during the mid 1980s was similar to the 1992 failure described above. There were two plutonium metal spheres packaged in the same design and size aluminum can. The secondary container was not breached; however, the aluminum can split like the one that was packaged with four feed balls. All the metal spheres that were originally packaged into this type of aluminum can were processed as part of the LLNL Inventory Reduction Program. The aluminum cans are no longer used for packaging plutonium at LLNL.

\section{Can Failure}

An incident report was generated on the plutonium storage can that failed in $1986 .{ }^{2}$ A summary of that report will be given here. Approximately 186 grams of scrap plutonium in various forms, along with box sweeps contaminated with graphite and possibly a few brush bristles, were packaged into a pint can during August 1985 under a dry nitrogen atmosphere. The nitrogen was contaminated with $300-400$ ppm oxygen. The can and its contents were bagged out of the glove box and the bag-out bag was twisted and taped. As described above, the can and bag-out bag were placed into a second bag that was sealed into a one gallon can as shown in Figure 4. The material was stored in the vault for approximately 15 months from August 1985 to November 1986. An inventory was performed in October 1986 and the gallon can was intact, but in November 1986, the gallon can was found to be partially collapsed as shown in Figures 5 and 6. There was no contamination on the outside of the can or in the vault storage compartment, nor did the can feel thermally warm. It was immediately transferred to a glove box where a closer inspection of the gallon can was made.

The can had the appearance of a can that would have been collapsed under vacuum. The lid was tightly sealed but labels on the can were discolored and there were signs of heat discoloration on the bottom of the can. As shown in Figure 7, the plastic bags around the pint size inner storage can burned away at areas where the inner can was

\footnotetext{
${ }^{1}$ John M. Haschke and Joseph C. Martz, "Failure of a Plutonium Storage Container: A Case Study," presented at the Department of Energy Plutonium ES\&H Vulnerability Assessment Meeting, Gaithersburg, MD, March 28-30, 1994.

${ }^{2}$ R. H. Condit, D. V. Fix, and H. J. Howe, "Incident Analysis/Plutonium Burn in Storage Can, 'LLNL Incident Report, 1/16/87.
} 
in contact with the outer can. The remainder of the bags were melted and charred. Both the inner can and its identification label were discolored and the plastic warning label originally attached to the can was melted. The inner can had been resting on its side during storage as shown in Figure 8. The can was discolored on the side where the plutonium would have been in contact with the can. The lid of the inner can had popped off and was sitting loosely in the groove of the can. It hadn't fallen completely off because the melted bags were holding it in place. Plutonium oxide coated the inside of the can. The plutonium metal that had not completely oxidized did have a greenish coating indicative of plutonium oxide. $\mathrm{X}$-ray diffraction analysis of the powder inside the can showed that the major phase was $\mathrm{PuO}_{2}$ and that there were trace quantities of $\mathrm{PuN}, \mathrm{a}$ plutonium-oxide-carbide mixture, plutonium oxychloride $(\mathrm{PuOCl})$, and graphite. Because $\mathrm{PuOCl}$ was detected, it is assumed that the polyvinyl chloride plastic bags generated some $\mathrm{HCl}$.

An analysis of the 1986 can failure has been attributed to the following chain of events. The stored metal fines reacted slowly with hydrogen, water vapor, or organic vapors originating in the floor sweepings or plastic bags to generate plutonium hydride. The pyrophoric hydride probably ignited which caused a sudden heat excursion that melted the bags surrounding the inner can. Air then diffused from the outer can into the inner can through small areas of incomplete sealing. An additional supply of air into the outer can may have occurred through the well-sealed lid. A leakage path of only a few microns effective diameter would be necessary for the passage of air into a container. Even though the gallon can was tightly sealed, it would be reasonable to expect an air passage of this size because the lid and rim of the can are not designed to be vacuum perfect. However, the seal of the outer can was sufficient to allow it to partially collapse as the reaction consumed oxygen and the pressure in the can was decreased. A reaction energy of 25 to 35 kiloJoules would be produced in the conversion of 6 to 7 grams of plutonium metal to oxide. The increase in pressure would likely be enough to pop the lid on the inner can if it weren't tightly sealed.

Another scenario of the can failure is as follows: if the inner can had been tightly sealed, the organic material inside the can may have undergone radiolytic decomposition and the pressure increase may have been enough to pop the lid off. The reaction with air diffusing through the plastic bags would have occurred, and the heat generation would have been sufficient to melt the plastic bags. Continuation of the oxide formation and implosion of the outer can would be as described above. Other cans containing similar types of material were retrieved from the vault and examined. There were no other problems encountered, although some of the metal had oxidized. 


\section{NON CAN FAILURE EVENTS}

\section{MSE Button Oxidation}

An approximately 2 kilogram plutonium metal button, about 4.5 inches in diameter, 0.5 inches in height, and rounded bottom with a 3 inch spherical radius is produced during the molten salt extraction (MSE) process. A stainless steel can as shown in Figure 9 was designed and manufactured at LLNL for long term storage of the MSE button. The can was constructed with 304 stainless steel and a lid that is fitted with six 1/4 inch bolts. A groove in the top of the can holds a viton o-ring to assure a good seal between the can and lid. The stainless steel cans have been very effective at preventing oxidation of the metal button. Except for a single button, no visible oxide has been seen on metal buttons-that were stored for more than three years in the special cans.

In April 1991, a 1.97 kilogram button was packaged in the special can and was stored in the vault until August 1992 when it was retrieved to repackage it for off-site shipment. During the 16 month storage period, the entire metal button oxidized as shown in Figure 10.

The special can was packaged slightly differently from those described above. The inner can was bagged out into a polyvinyl chloride bag, then placed into a second polyethylene bag, and finally into a cookie can rather than a gallon paint can. The cookie can lid slips onto the can and then tape is wrapped around the can and lid. Air would have been in the second bag and the cookie can.

For the metal to oxidize, air would have had to diffuse through the glove box bag and into the stainless steel can. The bolts on the stainless steel inner can were found to be slightly loose, so it is believed that air entered the can because the lid wasn't sealed properly or because there was a failure of the o-ring. Additional air leakage into the cookie can occurred because tape does not provide an effective seal at its lid. As shown in Figure 10, some of the oxide was present on the flange and o-ring groove of the can. This may indicate the transfer of oxide as the bags were pumped with changing weather and atmospheric pressure, or more simply, the spillage of oxide into the flange area as the can was bagged into the glove box. There was not a contamination event associated with the oxidation of the metal because the plastic bags surrounding the stainless steel can were still intact when the can was bagged into the glove box.

\section{Hanford Packages}

During the 1980s, LLNL received 39 cans packaged at Rockwell Hanford Operations with nominal 2.2 kilogram plutonium metal ingots. The americium 
concentration in the ingots was about 1.6 weight percentage and the cans felt thermally warm. The overall packaging of the metal varied, but in all cases each metal ingot was wrapped in aluminum foil in the innermost can. Any plastic tape or bags in the packaging configuration were discolored or completely melted. Figure 11 shows the inner can opened and the metal ingot with plutonium oxide on the outside of the aluminum foil. From tens of grams to more than a hundred grams of plutonium oxide was recovered from the packaging of each ingot. The oxide could be found both inside and outside the aluminum foil. Most of the inner cans were approximately one pint food pack cans that were sealed shut by a can sealer. A video of a food pack can being opened was made at LLNL. In this video, visible quantities of oxide could be seen escaping from the can as it was being opened with a can opener. Since all 39 cans were in this condition, it is assumed that the air inside the inner can oxidized the plutonium metal and that the bags and labels were thermally and radiolitically degraded. 


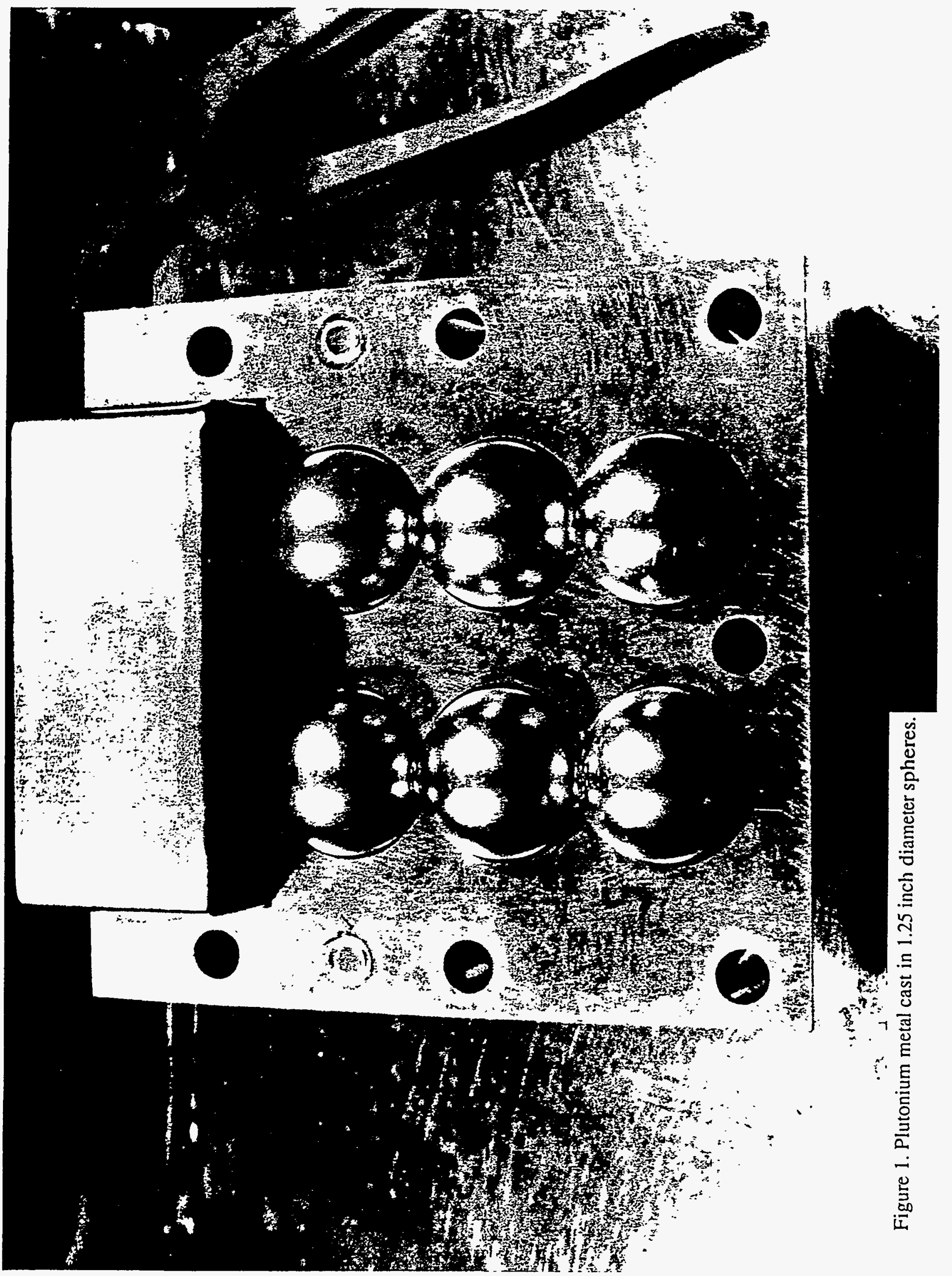




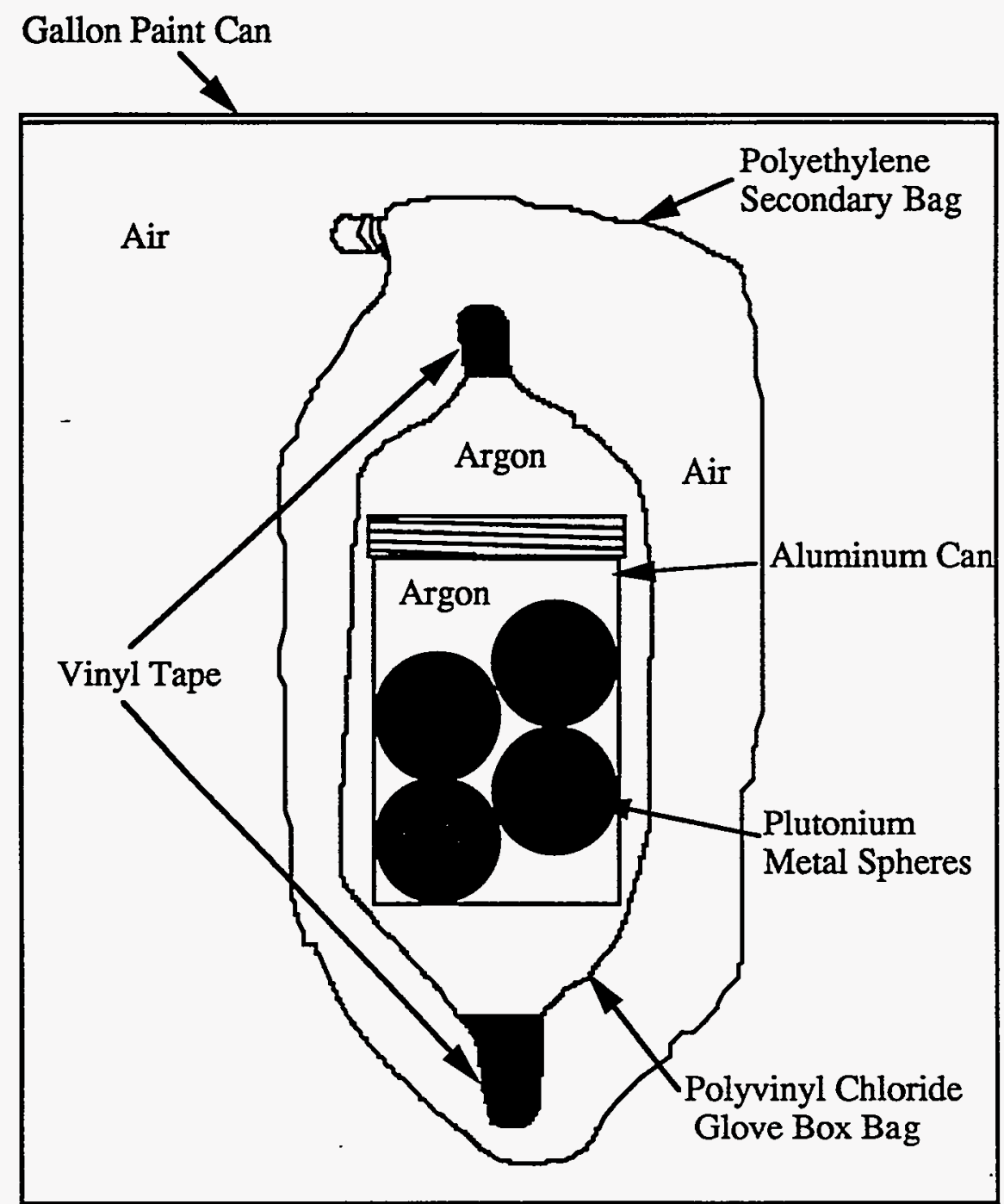

Figure 2. Packaging configuration for 1992 can failure 


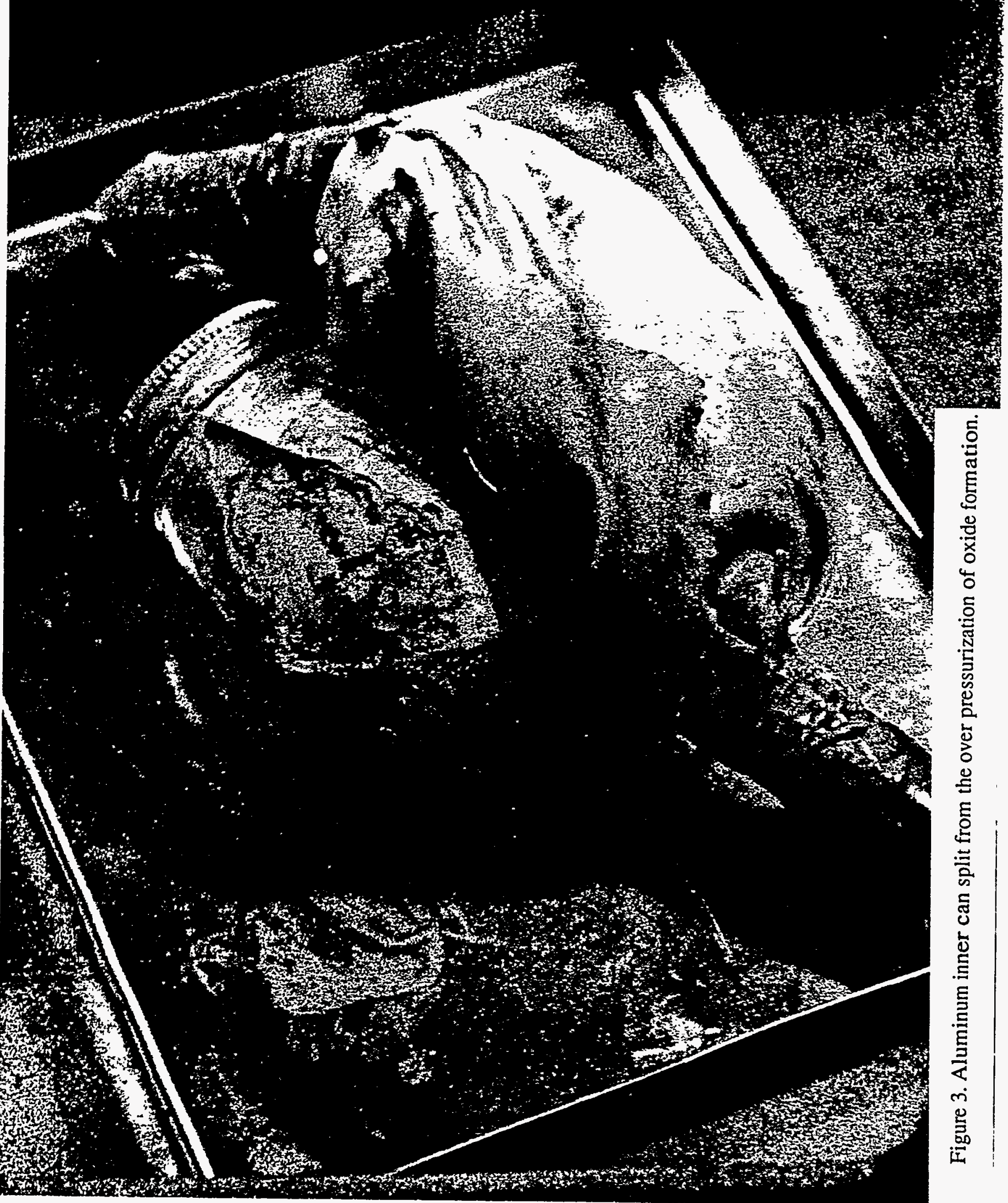




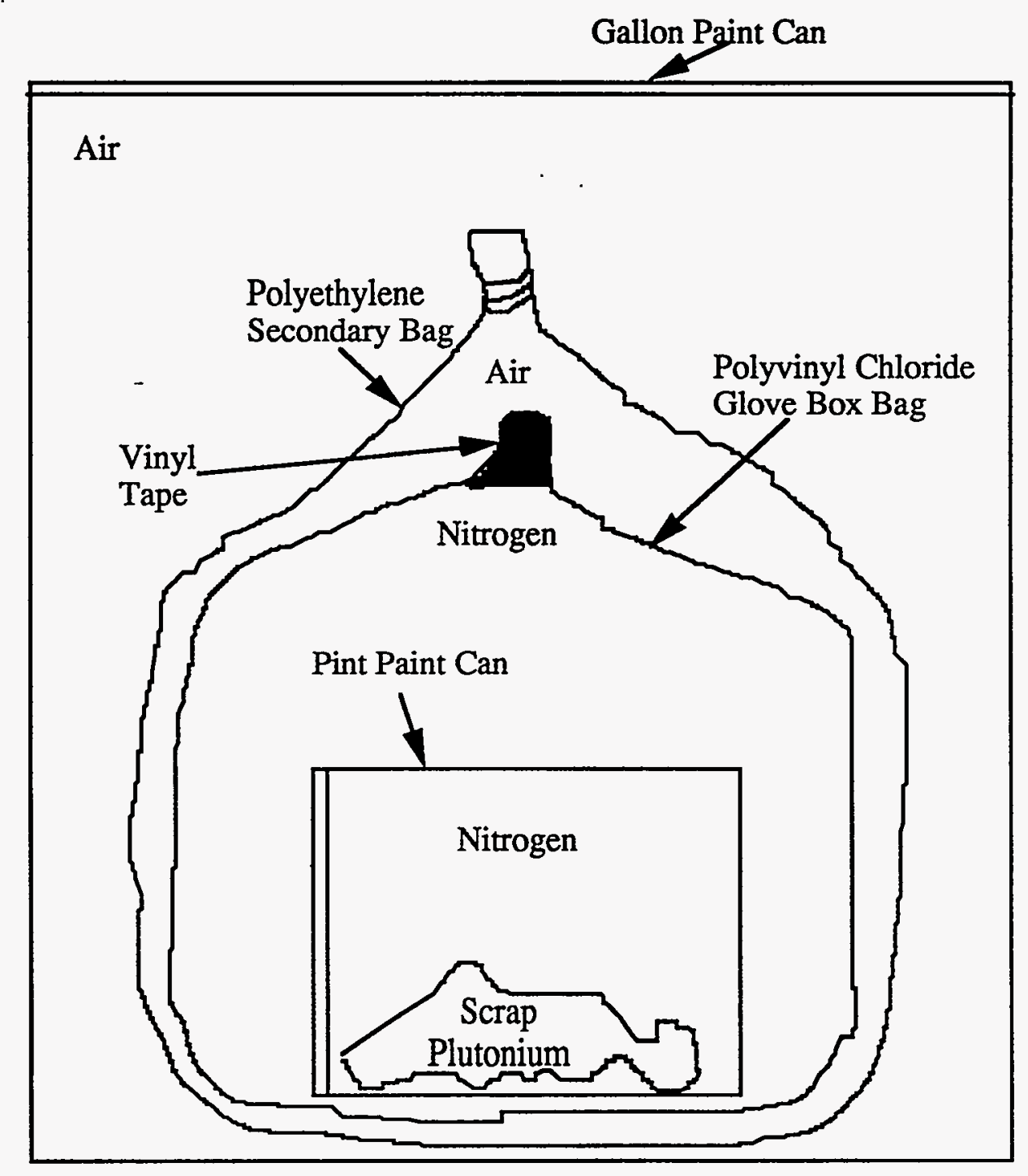

Figure 4. Packaging configuration for 1986 can failure. 


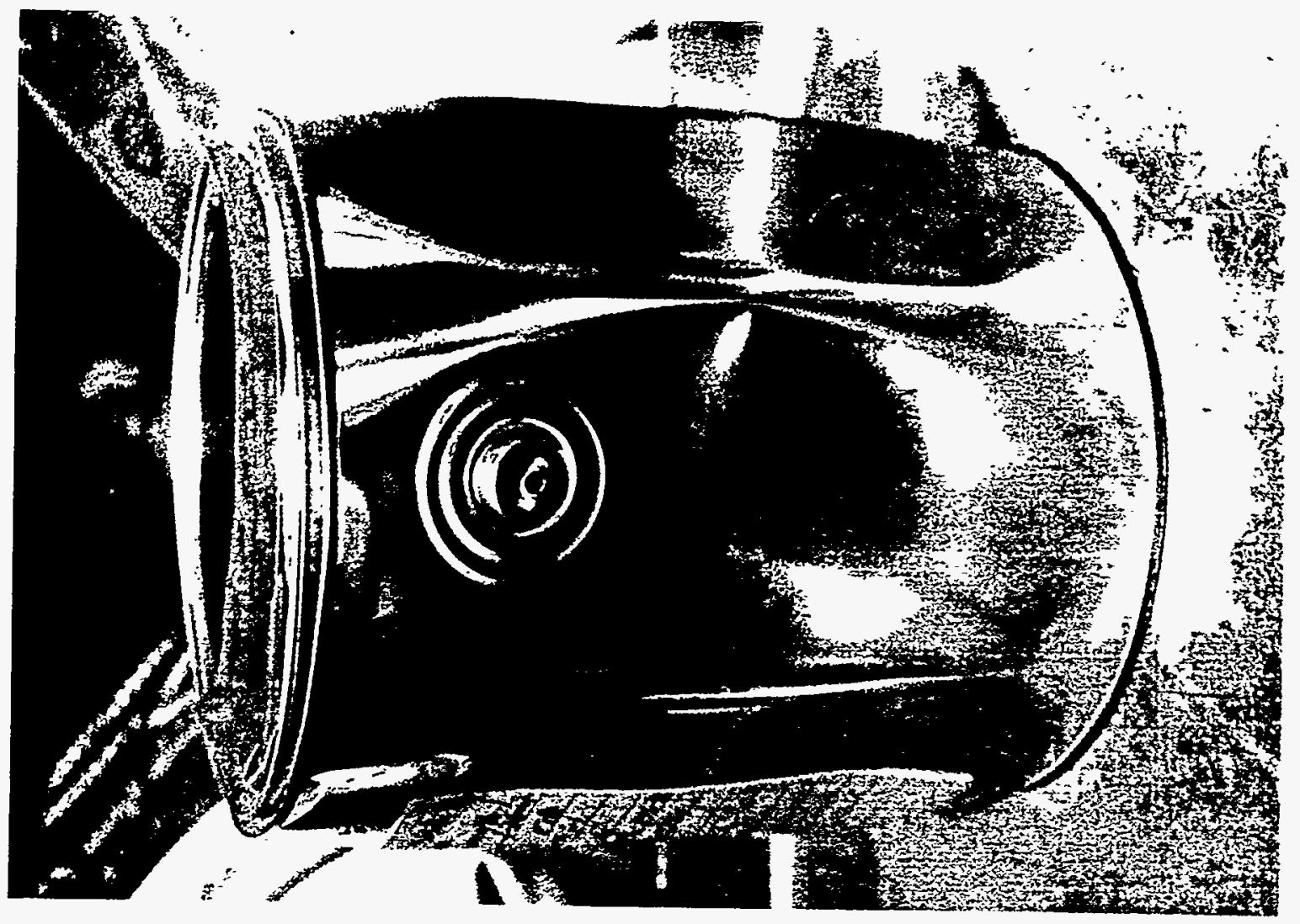

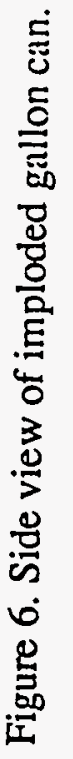

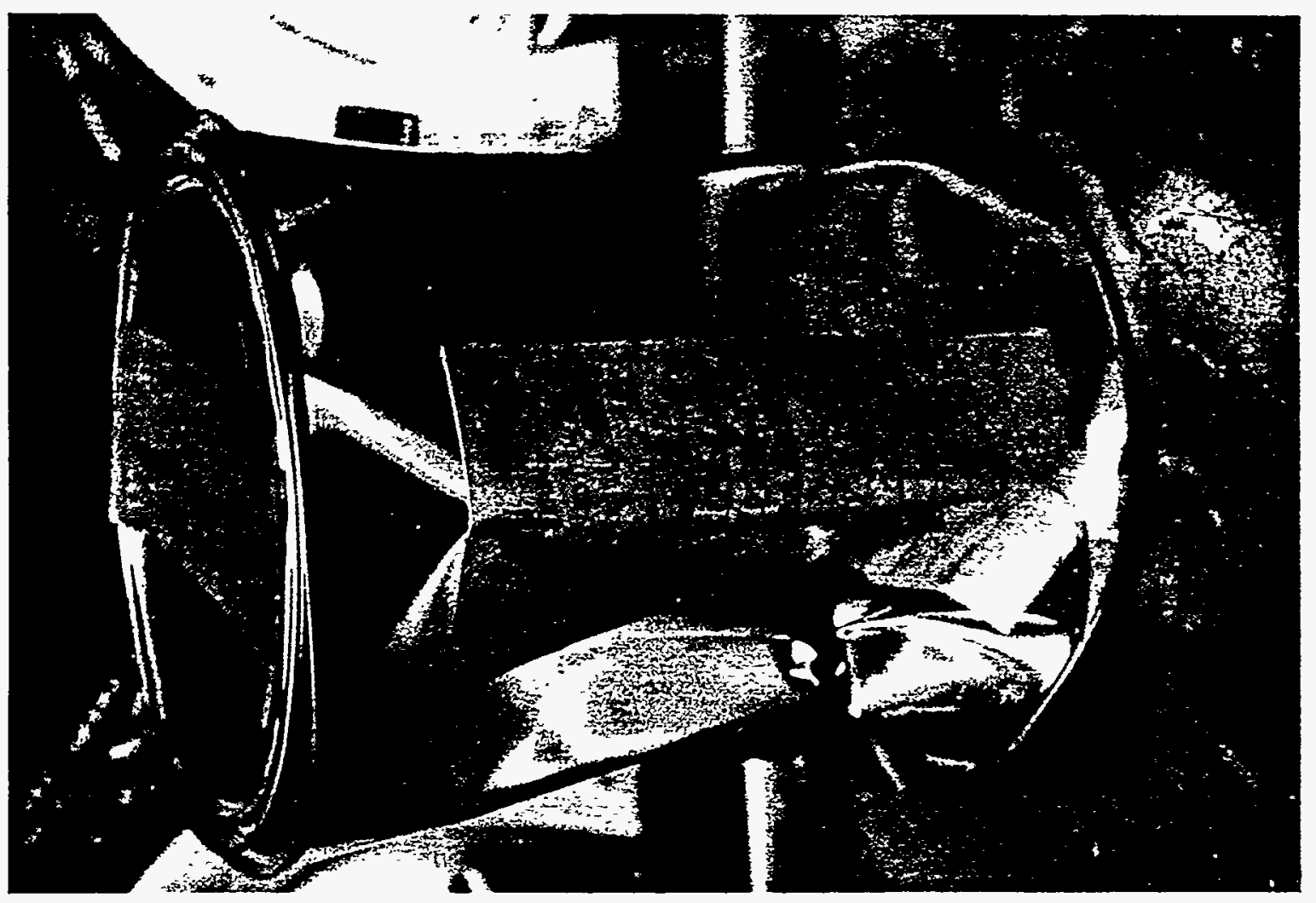

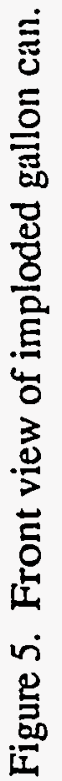




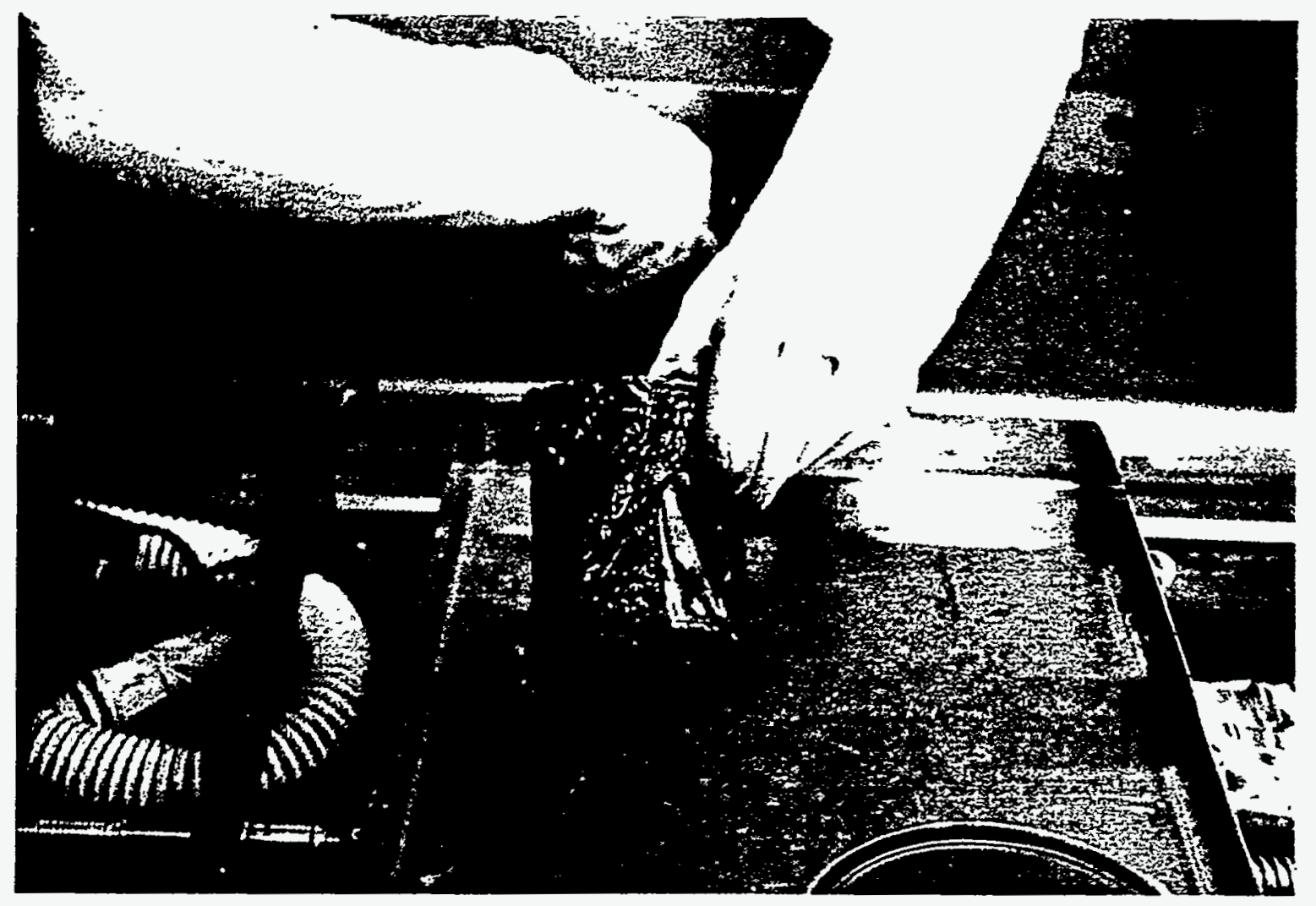

Figure 7. Melted bags around the inner storage can.

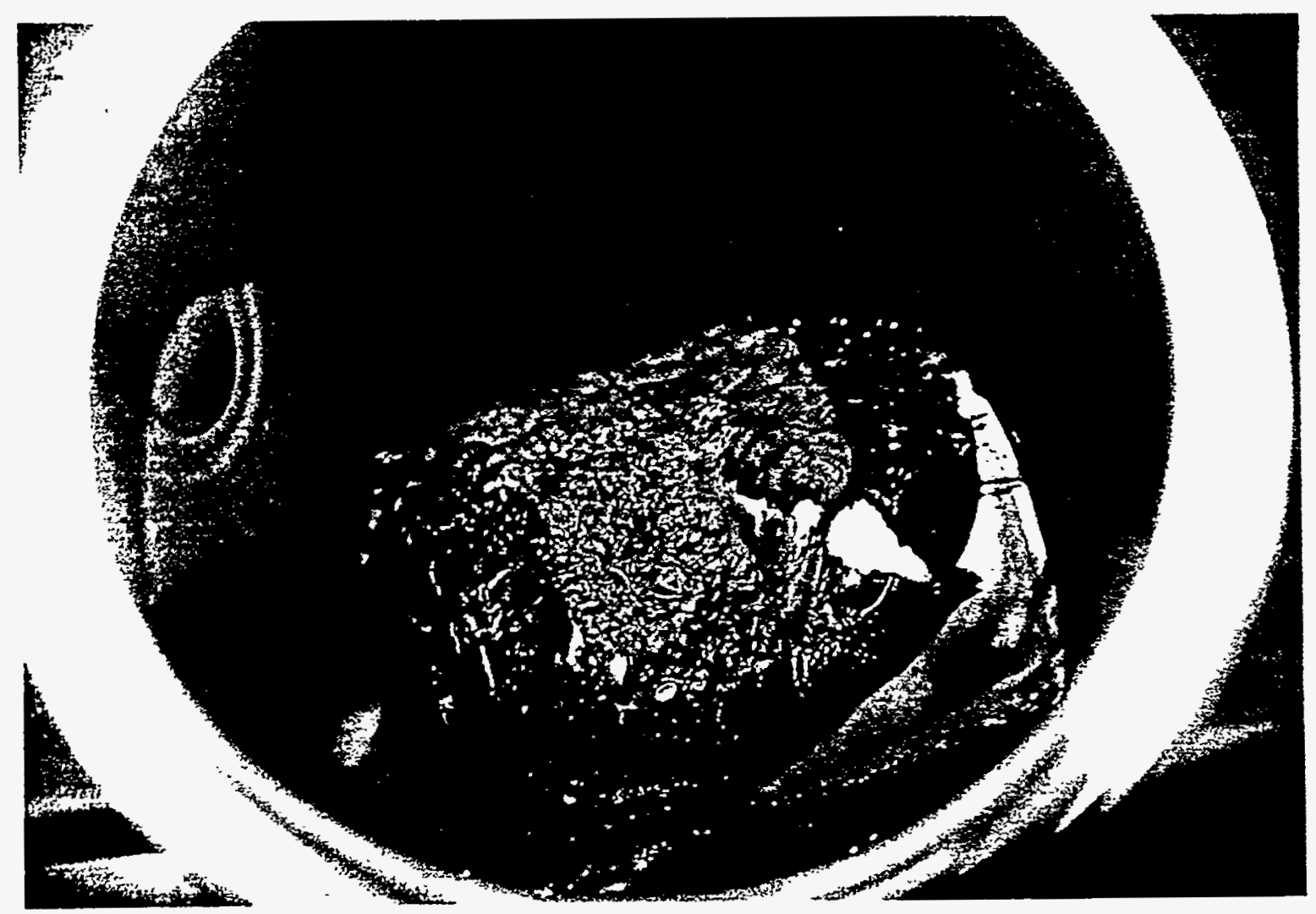

Figure 8. Inner can lying on its side inside the outer can. 

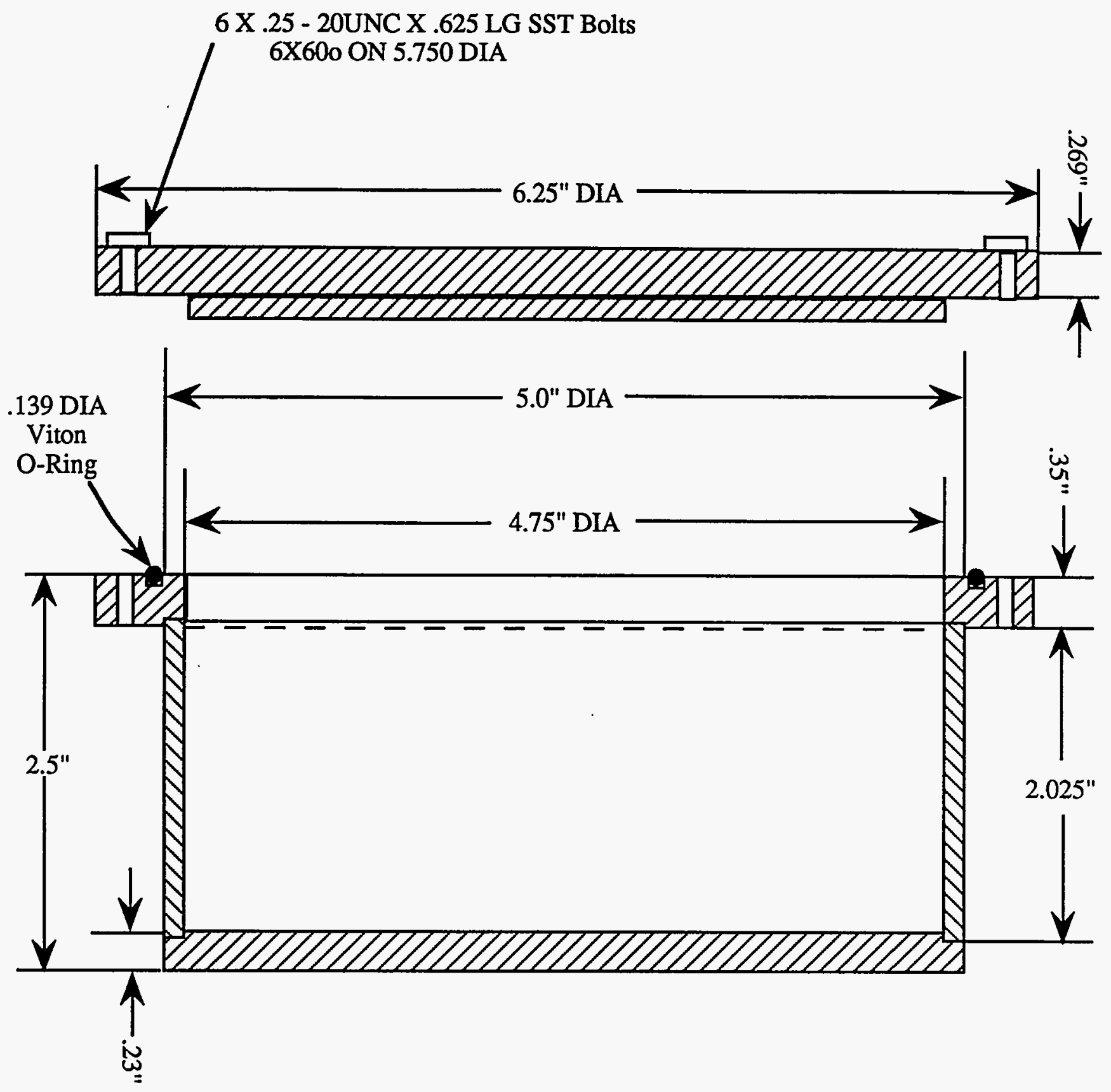

Figure 9. Plutonium storage can made of 304 stainless steel. 


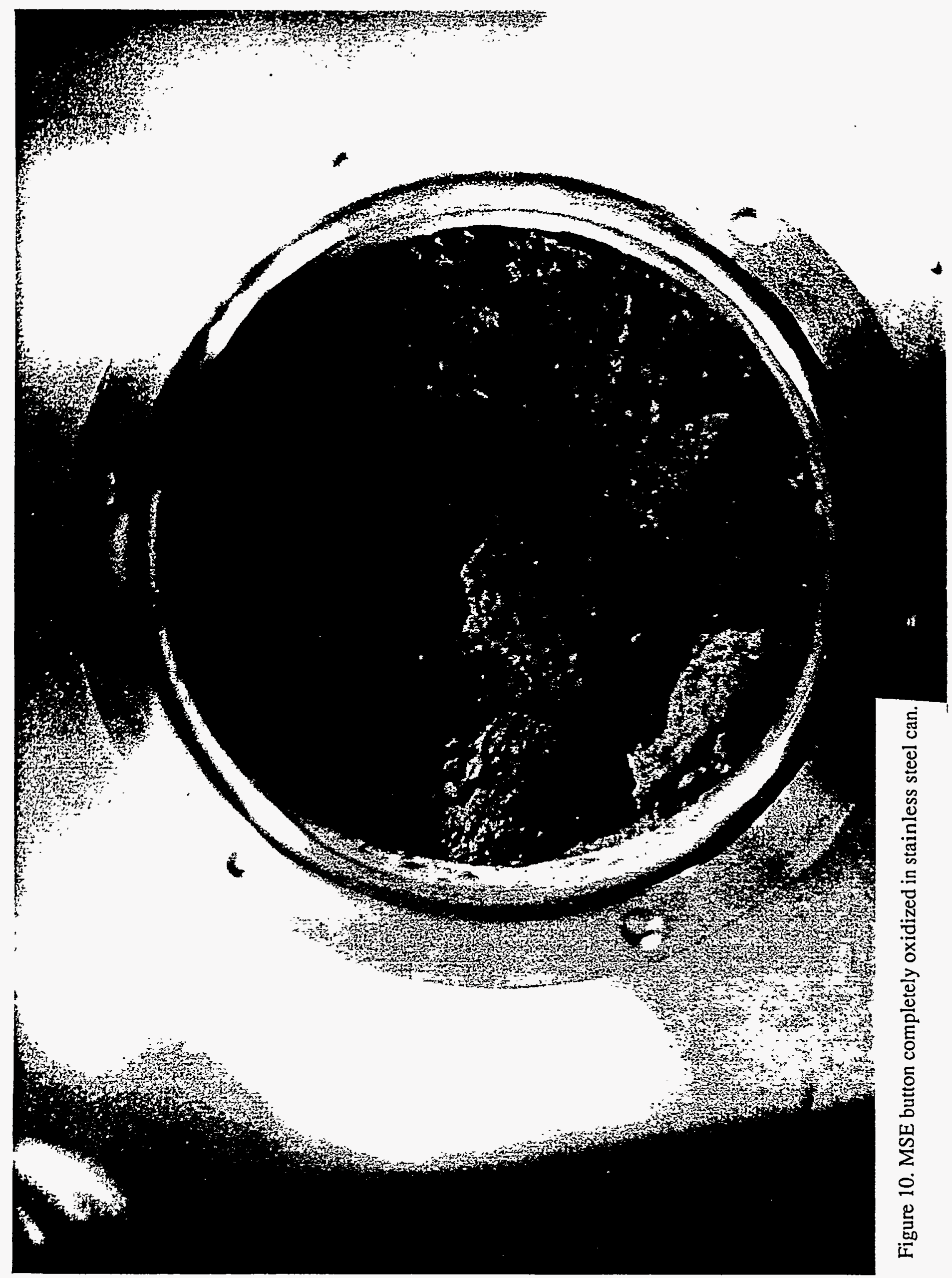




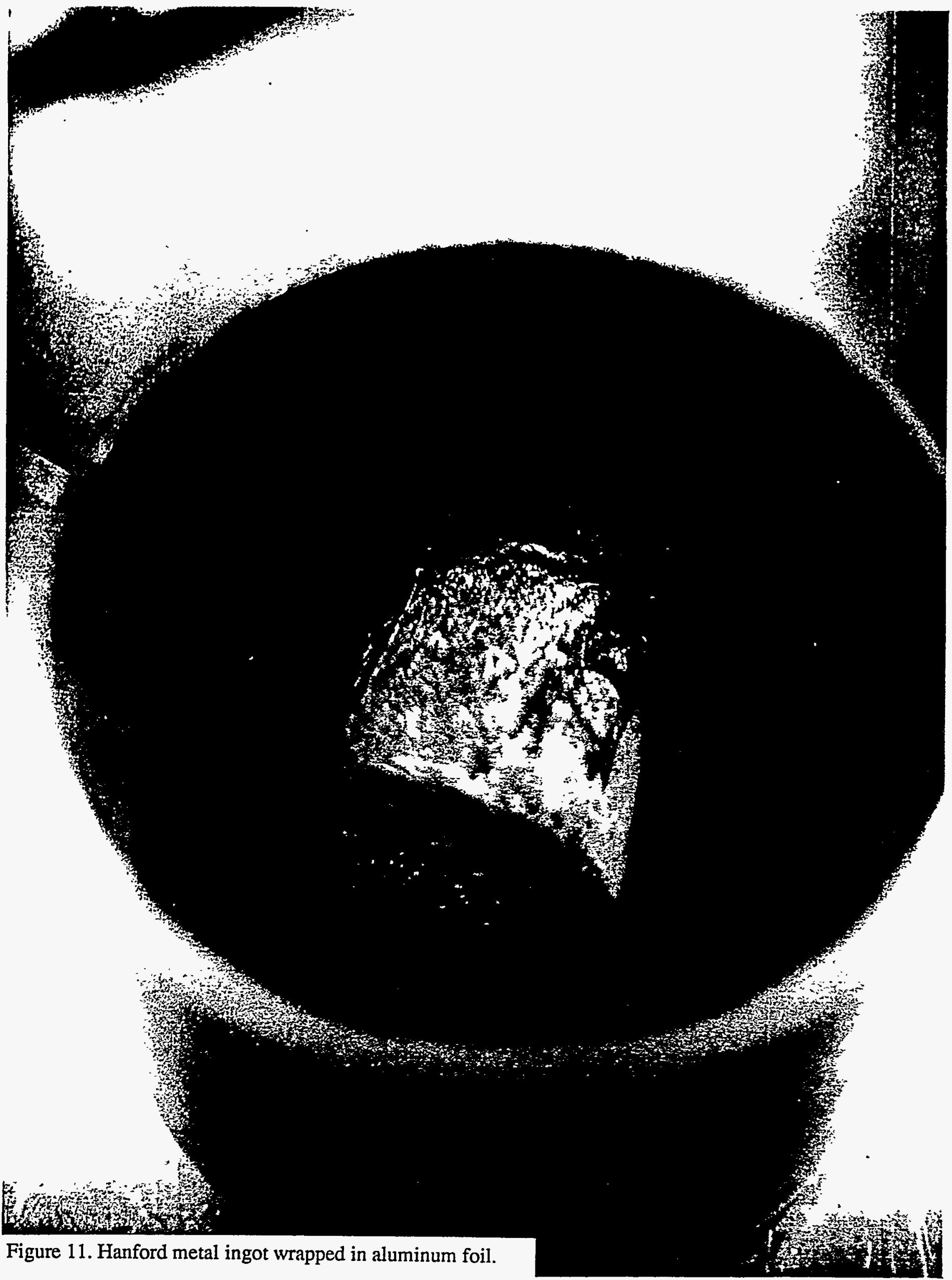

